\title{
A Framework based on Geo-Information Neural System (GINS) for Predicting Remaining Life of Heritage Buildings Assets
}

\author{
Ahmed Abou El-Fetouh \\ Mansoura University, Egypt \\ Faculty of Computers and \\ Informations \\ Department of Information \\ Systems
}

\author{
Hana Mohamed \\ Mansoura University, Egypt \\ Faculty of Computers and \\ Informations \\ Department of Information \\ Systems
}

\author{
Mohammed Shawky \\ Mansoura University, Egypt \\ Faculty of Engineering \\ Department of Architecture \\ \&Planning
}

\begin{abstract}
Preservation of cultural heritage of a community is essential to its identity and its transmission to future generations. Some prevention methods have been introduced for the preservation of cultural heritages such as buildings, monuments, structures, sites. These are based on basic principles and methodologies which are developed by experts from different areas.

The main objective of this study is to predict remaining life for heritage buildings through study the influence different geographic factors. These factors may be traffic, air pollution and destructive events that causing heavy damage like earthquakes, fire or war etc. All these factors threaten and destroy the heritage buildings and thus reduce its life. In this paper we discuss the integration between three technologies for preservation of Architecture Heritage at two stages. First stage, represent the integration between Geographic Information Systems and 3D Modeling technique. Through build 3D model to produce more realistic and detailed environment for preservation of heritage building and add to GIS database for spatial analysis. Second stage, Artificial Neural Networks is used to build the prediction model using the resulting data from first stage. The predicted results will then represented visually using 3D Modeling technique.
\end{abstract}

\section{Keywords}

GIS, 3D Modeling, AIS, ANNs, GINS, Architectural Heritage Conversation.

\section{INTRODUCTION}

Architecture Heritage is a substantial part of our cultural heritage. But other elements of our cultural heritage may be protected by putting them behind a glass in a museum. Architectural monuments are widely used and endangered by long term geographic influences. But by all means when monuments are seriously damaged, or completely destroyed, the amount and quality of any surviving documentation becomes highly important. Therefore, it is necessary to document the actual state of the architectural monuments in a manner. This opens the opportunity to detect continuous damage by change detection techniques and to

restore the monument in case of heavy damage. Before starting to acquire new data on the monument already existing data sources have to be obtained, e.g. existing plans of previous restorations, ancient pictures or documentation's of architectural research projects [1].
Today, information technologies are used instead of traditional methods to get more precise data and to save time. Therefore, 3D modeling and visualization are important tools in the field of cultural heritage. They can be used in the area of documentation of architecture heritage and planning of architecture heritage restorations. They also provide comparing the existing situation with the future situation after restoration works [2]. It was achieved to develop a three dimensional (3D) virtual model of the EL-Shenawy Palace and interactive visualization of the model via computer. EL-Shenawy Palace is an architectural heritage building with its historical value. Its history is dating back to 1928. It is located in Mansoura, Dakahlia, Egypt. It is also one of the historical and an important building which is the Palace got a certificate of the most beautiful palace built outside of Italy signed by the Italians in the hands of Mussolini [3]. One of the aims of this study is to integrate the 3D model into Geographic information systems.

Knowledge and information are the main steps for the preservation and the valorization of the whole architecture heritage. This means that a more and more active historicalscientifical document research is necessary to provide the respect for identity and singularity during years [4]. Geography is an important discipline which has a great impaction on individuals, businesses and governments. So, GIS was developed and appeared in 1960. It can be defined in summary as a set of tools for storage, retrieval, analysis and display of spatial data. Actually it differs from traditional information systems in its ability to work with both spatial data and attribute data. Spatial data describes the locations and shapes of geographic features like rivers, roads, buildings and streets, while attribute data describes the characteristics of geographic features.

GIS similarly as a collection of computer hardware, software, and geographic data for capturing, managing, analyzing, and displaying all forms of geographically referenced information .This means all possible tools which used in processing and analyzing of spatial data into useful information. This information is used in decision making process and in solving complex geographical problems.

GIS includes set of functions to support the acquisition, storage, querying, analysis and visualization of spatial data. These functions are called "A heart of GIS" according to. They can be categorized into three main types: Input, storage and editing functions, Analysis functions and Output functions [5]. 
3D models and GIS give clear and detailed information of existing situation of the objects. They can be used for comparing the existing situation with the future situation after restoration or previous situation after a disaster. GIS and 3D Modeling information can become increasingly more valuable for decision making when coupled to artificial intelligence (AI).

Artificial Neural Networks (ANNs) is one of soft computing techniques which are a branch of AI. It is an information processing paradigm that is inspired by the way biological nervous systems, such as the brain process information. The integration of ANN modeling in GIS can be applied in many applications to improve decision making process. When linked to GIS, artificial neural networks can be useful for evaluating, monitoring and decision-making. ANN is chosen with GIS because of its powerful capabilities in modeling and simulation. While GIS is used in collecting, management and querying of spatial data, ANN is used to extend the functionalities of GIS to include modeling and simulation capabilities [5].

This paper is organized as follows: In section2we reviewed briefly some of the recent related work published in the area of integration between GIS, 3D Modeling Technique and Artificial Neural Networks; section3 Explain the framework for GeoInformation Neural System at two phases. First phase provides Architectural Information System and its importance in architecture heritage preservation. Second phase, Build the prediction model by ANNs using the resulting data from first phase; section 4 concludes the research.

\section{RECENT RELATED WORK PUBLISHED IN THE AREA}

Besides the introduction given above, a literary review is presented on GIS, 3D Modeling and ANNs through their journey from inception to be implemented in various problems.

Hasan YILDIZ, M. Umit GUMUSAY [2].Aimed to develop a three dimensional (3D) virtual model of the Çukursaray (the Hollow Palace), Istanbul-Turkey and to integrate this model into the campus information system. The need of the 3D models to produce more realistic and detailed environment. Using 3D models and visualization objects in GIS applications provides users an interactive visual exploration of 3D digital environment of a campus. In addition, using them increases the spatial reality and makes the processing of spatial data more efficient.

Franca RESTUCCIA1, Mariateresa GALIZIA1, Cettina SANTAGATI1 [4]. In the perspective of creating a fundamental cognitive framework of Catania's urban environment. The research team's attention aimed at designing a GIS for Urban Architecture, elaborating a structure that is able to collect data inside a defined and interrelated logic archival system conceived like an open and flexible database, which can immediately be consulted and constantly implemented. It is a multiscale system which can be navigated through its contents (texts, drawings, 3D rendering, pictures, and historical documents).A system which allows the integration of several documents in a common geodatabase up to visualize the most meaningful details.By means of the creation of a GIS and 3D Model for urban cultural heritage, urban environment becomes like a "hypertext"organized by on-line archival that memorizes structured information concerning different objects, placed intheir spatial position and defined by their reciprocal topological relations. An elastic structure, organizedaccording to logical criteria that go from the general to particular without conditioned sequential paths.
F. Karsli a, *, E. Ayhan a, E. Tunc a [8]. In this study, Opera House in Hannover (Germany) was choosing as a historical building. Design and application of an architectural information system has been realized in a simple sense. The basic components of the system are digital photogrammetry and GIS An integration between the 3D model of object generated from photogrammetric techniques and attribute data concerning the same model of object has been provided. With this integration, the data will be continually updated, analyzed and queried. Aspect of the documentation, registration and observation of historical objects, two techniques used is nicely proportioned. The results of the study confirm that the management and observation of the historical buildings with proposed AIS was done very easily and effectively.

Ahmed Loai Ali, Osman Hegazy, Mohammed NourEldien[5]. The application aims to build prediction model using ANN to predict the distribution of slum in the future in Cairo. Then it presents a spatial representation of slums in this time as a visualized map.The results of the application will be a map of thedistribution of slum areas in Cairo in 2016. In the proposed model GIS is used as a good management tool for spatial data. It is used to prepare, organize, display and visualize spatial data while ANN is used to build the slum prediction model (trainvalidate-test) using collected data by GIS. The predicted results will then represented visually using GIS. These representations will facilitate to decision makers and policy planners to take correct actions. We consider spatial representation of slum is the missing link toward problem solving. This application used statistics studies applied on Cairo in period from 2006 to 2016 to develop two types of prediction models, one of them depending only on scoio-economic factors only, while the other depending on physical factors only.

Table 1. Slum prediction model resulting from physical factors.

\begin{tabular}{|c|c|c|}
\hline Shyakha Name & $\begin{array}{c}\text { Status in } \\
\mathbf{2 0 0 6}\end{array}$ & $\begin{array}{c}\text { Status in } \\
\mathbf{2 0 1 6}\end{array}$ \\
\hline Barkat Elnasr & Semi slum & Non slum \\
\hline Barkat Elhag & Semi slum & Non slum \\
\hline Elmatar & Semi slum & Non slum \\
\hline \multicolumn{3}{|c|}{ Adjacent to them in order } \\
\hline Kafr Abo Seer & Non slum & Semi slum \\
\hline Alhaykstep & Non slum & Semi slum \\
\hline Sheraton Elmtar & Non slum & Semi slum \\
\hline
\end{tabular}

Table 2. Slum prediction model resulting from scoioeconomicfactors.

\begin{tabular}{|c|c|c|}
\hline Shyakha Name & $\begin{array}{c}\text { Status in } \\
\mathbf{2 0 0 6}\end{array}$ & $\begin{array}{c}\text { Status in } \\
\mathbf{2 0 1 6}\end{array}$ \\
\hline Azbat Elhagana & Semi slum & Slum \\
\hline Elzyton Alkablia & Semi slum & Slum \\
\hline Alsrayat Elshrkia & Non slum & Semi slum \\
\hline Elmatnqa Elashra & Non slum & Slum \\
\hline Alwafa w Alamal & Non slum & Slum \\
\hline Zenhom & Semi slum & Slum \\
\hline
\end{tabular}

Abdul GhaniSarip [11]. An Automated Valuation Model (AVM) named "Geo-Information Neural System" (GINS) is developed as an alternative for use in the valuation of single-residential property. This system integrates a Geographic Information System (GIS) technique with Artificial Neural Networks (ANN) 
modeling. The trained neural network model is then used to predict the probable value of a residential property. The model is built on a GIS platform, which will allow for GINS automation as well as the conduct of interactive valuations. A graphical user interface is developed for seamless integration and user interaction. It involves the establishment of a GIS database management system for all detached property in Damansara Heights, Kuala Lumpur. A sample of 100 sales of detached houses is taken for predicting sales price for them. The trained neural network model is then used to predict the probable value of a residential property.

Table 3. Data Representation

\begin{tabular}{|c|c|c|c|}
\hline Attributes & Data Types & $\begin{array}{c}\text { Value (Min } \\
- \text { Max) }\end{array}$ & Representation \\
\hline $\begin{array}{c}\text { Selling price } \\
\text { (RM mil) }\end{array}$ & Continuous & $1.50-5.65$ & Numeric \\
\hline Lot area (sqm) & Continuous & $\begin{array}{c}441.000- \\
1275.331\end{array}$ & Numeric \\
\hline $\begin{array}{c}\text { Building } \\
\text { MFA (sqm) }\end{array}$ & Continuous & $\begin{array}{c}158.500- \\
568.734\end{array}$ & Numeric \\
\hline $\begin{array}{c}\text { Building AFA } \\
\text { (sqm) }\end{array}$ & Continuous & $\begin{array}{c}22.000- \\
380.000\end{array}$ & Numeric \\
\hline Building age & Continuous & $2-35$ & Numeric \\
\hline No. of storey & Discrete & 2,3 & Numeric \\
\hline $\begin{array}{c}\text { No. of } \\
\text { bedroom }\end{array}$ & Discrete & $3,4,5,6$ & Numeric \\
\hline $\begin{array}{c}\text { Repair } \\
\text { condition }\end{array}$ & Categorical & $\begin{array}{c}\text { Good, } \\
\text { Average }\end{array}$ & One-of-N code \\
\hline $\begin{array}{c}\text { Finishes } \\
\text { quality }\end{array}$ & Categorical & $\begin{array}{c}\text { Good, } \\
\text { Average }\end{array}$ & One-of-N code \\
\hline $\begin{array}{c}\text { Distance to } \\
\text { exit points } \\
\text { (km) }\end{array}$ & Continuous & $0.1-5.0$ & Numeric \\
\hline $\begin{array}{c}\text { Distance to } \\
\text { commercials } \\
\text { (km) }\end{array}$ & Continuous & $0.05-3.5$ & Numeric \\
\hline $\begin{array}{c}\text { Distance to } \\
\text { schools }\end{array}$ & Continuous & $0.05-3.5$ & Numeric \\
\hline
\end{tabular}

Table 4. Results of ANN Predictive Modeling

\begin{tabular}{|c|c|c|c|c|}
\hline No. & $\begin{array}{c}\text { ANN Model } \\
\text { Output } \\
\text { (RM mil) }\end{array}$ & $\begin{array}{c}\text { Actual } \\
\text { Property Price } \\
\text { (RM mil) }\end{array}$ & $\begin{array}{c}\text { Value } \\
\text { Difference } \\
\text { (RM mil) }\end{array}$ & $\begin{array}{c}\text { Error } \\
(\%)\end{array}$ \\
\hline 1 & 1.947 & 2.100 & -0.153 & 7.86 \\
\hline 2 & 2.193 & 2.030 & 0.163 & 7.43 \\
\hline 3 & 2.538 & 2.480 & 0.058 & 2.29 \\
\hline 4 & 2.071 & 2.000 & 0.071 & 3.43 \\
\hline 5 & 1.776 & 1.750 & 0.018 & 1.02 \\
\hline 6 & 2.205 & 2.300 & -0.095 & 4.31 \\
\hline 7 & 1.788 & 1.680 & 0.108 & 6.04 \\
\hline 8 & 2.895 & 1.100 & -0.206 & 10.87 \\
\hline 9 & 2.334 & 2.180 & 0.154 & 6.59 \\
\hline 10 & 1.807 & 1.900 & -0.093 & 5.15 \\
\hline
\end{tabular}

FatimaZohraYounsi*,

DjamilaHamdadou*, KarimBouamra*[13].

Aims to propose a decision-making model structured by the application of Geographical Information Systems (GIS) that can describe and analyze the decision and Artificial Neural Networks (ANN) context to synthesize these data to assist decision makers in their choices. The decisional model has been designed to meet the different goal (social, economic and environmental).GIS manages information describing the territory and offers spatial analysis operators. These tools allow taking into account the context of the considered project and also identifying and describing various alternatives. Neural network methods are then used to treat this information and choose most adequate solutions. This study applied on an area in the canton of Vaud(Switzerland) to approximately $15 \mathrm{~km}$ in the north ofLausanne.

This study aims to build prediction model to predict the remaining life of heritage buildings in the future. Through develop a three dimensional (3D) virtual model of El-Shenawy Palace and to integrate this model into Geo-Information Neural System. InPhotogrammetric application, 3D model building started with the acquisition of the sufficient image data and was completed by constructing graphical data to produce more realistic and detailed environment of heritage building. After that, GIS is used as a good management tool for spatial data. It is used to prepare, organize, display and visualize spatial data, graphic and non-graphic data related to a heritage building were collected to integrate and update information about created 3D model and GIS infrastructure was built depending on database design. While ANN is used to build the prediction model using collected data by GIS. By this way GIS will become more intelligent as including modeling and simulation capabilities. This coupling can be used for many applications for the purposes of improved decision-making.

\section{AFRAME WORK FOR GINS}

The framework of this study can be composed of integration between two phases. First phase, represent integration between photogrammetric techniques (3D Models) and GIS. This integration called Architectural Information System (AIS).Second phase, Build the prediction model using ANNs depend on the resulting data from GIS. This integration called Geo-information Neural System (GINS).

\subsection{Architectural Information System}

Architectural heritage must be conserved by using contemporary approaches. Conserving the historical buildings depend on appropriate measurements and data related to their life history. Conservation process includes the collection, evaluation, analysis, visualization and continuous monitoring of data collected from the historic building. The historic building can be evaluated with respect to three basic data groups; the building itself with its surrounded site scale, the spaces of the buildings and the components of the building [9].At this stage, digital photogrammetric (Photorealistic) techniques and GIS (Geographic Information System) integration would be one of the best solutions. GIS has a capability to integrate and update graphic and non-graphic data according to user inputs. In this section, the important point was to evaluate the whole building as a complete model in order to visualize the building on different data topics with all components. 3D model of historical buildings is constituted by using photogrammetric techniques, and added to GIS database to carry out querying, updating and analyzing their properties. As a result, in this study, an example of photogrammetric and GIS integration has been presented to conserve the historical buildings as a simple Architectural Information System (AIS) [8]. 
So, 3D modeling is becoming an important tool for monitoring and preserving Architecture heritage.3D modeling is the process of developing a mathematical and geometrical representation of any three dimensional object. The role of the $3 \mathrm{D}$ modeling and visualization in the field of cultural heritage is recognized as an important conservation, protection, analysis, development and management tool [2]. Sometimes Called Visually Realistic Model (VRM) because its ability for Simulating real world and reconstructing planned projects trains the related user to evaluate possible results. 3D models make perceiving real world easy and show what is going to change and happen at the end of a new design. It explains the result of recommended changes visually. Visualization objects and using 3D models in Architecture heritage increase the spatial reality and make the processing of spatial data more efficient. Because, a 3D model represents objects more realistic than a graphic based object. The biggest advantage of the $3 \mathrm{D}$ model is its mobility and its convincing effect on users for future decision making processes [10].

As a result of this stage has to include not only the graphical knowledge but also some no graphical information such as objects' history, conservation status, name of the quarter, name of the street, number of the door, functionality of the building, basement, medium floor, roof, total floor, condition of the building, registration, name of the building, construction date, financer, style of the building and owners. Using 3D models and visualization objects in GIS applications provides users an interactive visual exploration of 3D digital environment.

In addition, using them increases the spatial reality and makes the processing of spatial data more efficient. GIS became more important since it is used as a visual and analytical tool. Because it helps the users to understand spatial information and supports decision making process.

In this section, 3D modeling of the EL-Shenawy Palace and its application for Architecture information systems consist of following steps [2]:

- Data acquisition.

- Generation of a 3D model.

- Visualization of the 3D model.

- Importation of the 3D model into GIS.

The digital photogrammetry and the GIS provide a group of advantages and benefits in the architectural tasks impossible to obtain with such an efficiency, velocity and economy by means of other procedures. These advantages and benefits are among others [8]:

- Digital Photogrammetry and GIS allow us not only to edit some plans with a high degree of graphic precision and metric accuracy, but also to detect all those defects or structural and constructive degenerations that cause the minimum deformations or alterations in the formal state of the building.

- To have a graphic database of quality, which can work in a coordinated way, all the professionals involved in the cataloguing and preservation tasks.

- To provide a basic instruments for the coordination and pursuit of the works and carried out studies or to develop.

- To facilitate the access, manipulation and bring up to date of all the information.

- To reduce the costs, so much in the obtaining of the data, like in the later tasks to carry out during the documentation process, restoration and preservation.
- To facilitate the exchange of data between diverse organisms and companies whose performances can impact or to influence in the environment of the monuments.

In our project, forming AIS is aimed with acquisition data by Digital Photogrammetric techniques and visualizes it in 3D with GIS environments. Different queries on 3D model of object have been done by linking graphical and attribute data. Briefly, our system has two main components; a digital photogrammetric system that we constitute a 3D model of the architectural object and the database management system that we performed a relationship between graphic and attribute data of the object.

\subsection{Artificial Neural Networks}

The main aim of this work is to develop a framework for this integration to be used later as a general framework in many fields. Here, ANN is used with GIS to develop a prediction application. This integration is called marring between GIS and ANN. In this integration all functionalities will be used and directed to support decision-making process [4].

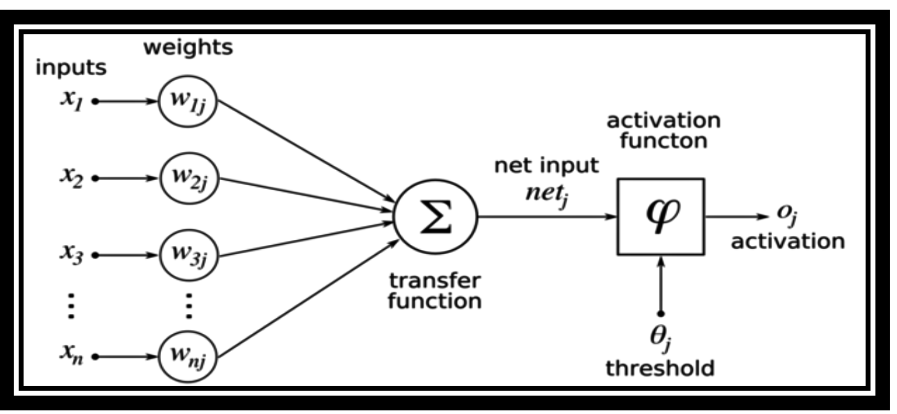

Fig1: A generic ANN model[11].

Artificial Neural Networks is a system of a massively distributed parallel processing that has a natural propensity for storing experiential knowledge. An ANN is composed of a set of nodes and a number of interconnected processing elements. ANNs use learning algorithms to model knowledge and save this knowledge in weighted connections, mimicking the function of a human brain. The nodes generally have three layers: input nodes, hidden nodes and an output node.

Many researchers have approved that ANN is unique by its model structure and algorithms that are not only intelligent, but can emulate comparison approach and can be applied to prediction and regression tasks in valuation analysis.

The most popular ANN model used in prediction and regression tasks is the Multi-Layer Perceptron (MLP) with Feed-forward Back-error Propagation (BP) type of learning algorithm or simply as MLP-BP [12].

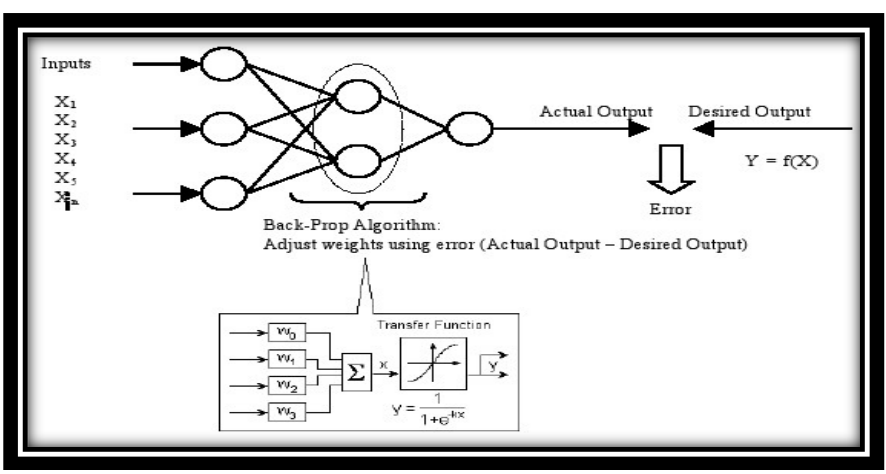

Fig 2: ANN MLP-BP model [12]. 
The integration between a Geographic Information System (GIS) technique with Artificial Neural Networks (ANN) modeling named Geo-Information Neural System (GINS).Sometimes called An Automated Valuation Model (AVM). Automated valuation modeling (AVM) is one of the new techniques in assessing single-property value. The model is built on a GIS platform, which will allow for GINS automation as well as the conduct of interactive valuations. GIS is utilized for location distance measurements, spatial queries and thematic mapping whilst ANN is employed to replicate the way the human brain might process spatial data by learning relationships, in this case the one existing between building characteristics such as physical and location attributes and remaining life value. This section describes briefly how the integrated system between GIS and ANN work. In this framework the GIS by its functions will be responsible of treating spatial data, while ANN will be responsible of modeling section. Here is a simulation of a working mechanism [5]:

1. User inserts a related data and maps using GIS interface.

2. GIS\&SDB functions are used to abstract and extract an important data and knowledge which may be has an effect in classification or prediction task.
3. Data transformation is a critical step in which you have two ways according to two types of spatial data:

- Raster data form: the value of interested data for each pixel is transformed into one dimensional array as a record in an input dataset.

- Vector data form: the related data is extracted from attributed data tables and stored in separate DB to be an input to ANN.

4. Training dataset constructed and then inserted to ANN components which build an appropriate model (classification or prediction model) according to the desired task.

5. ANN after construction and training of the model, adjustment and optimization functions are then used to adapt the developed model.

6. Using the model will be the remaining task by inserting an input dataset and get an output results.

7. The final step will be using 3D visualization techniques and GIS interface to represent the results in an understanding form (map and 3D Model) to facilitate the task of decision makers.

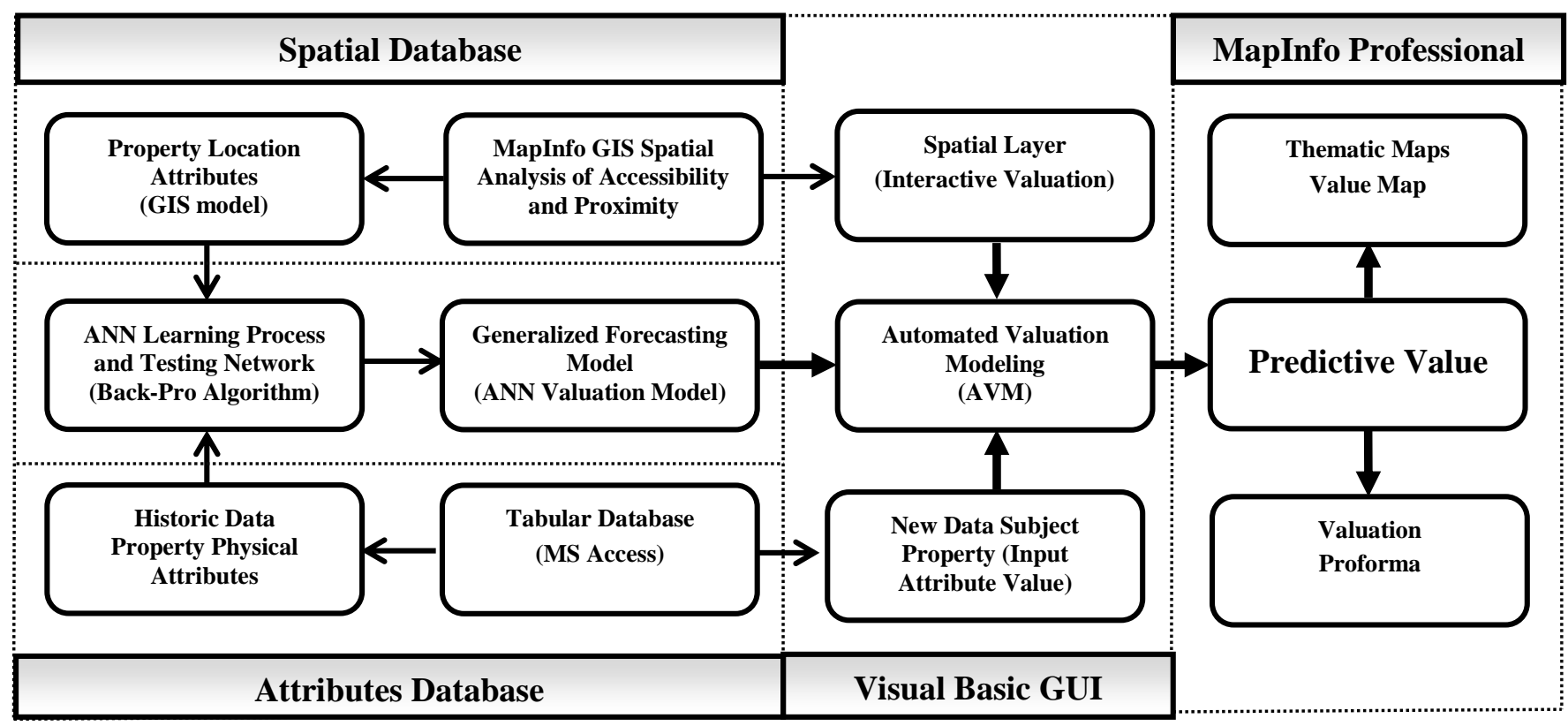

Fig 3:GINS conceptual design 


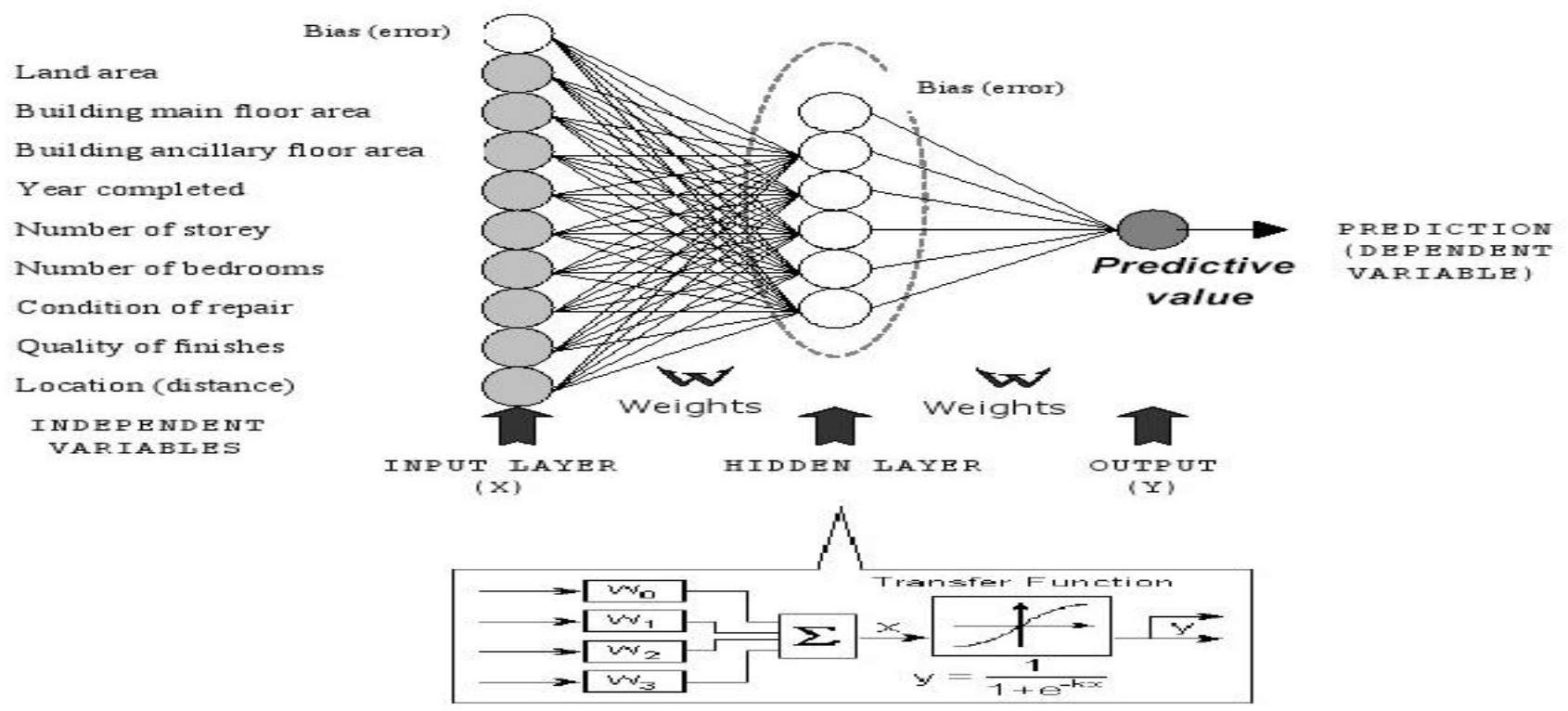

Fig4: ANN property valuation model [11].

The application mechanism can be summarized as the following steps. 1st geographic data and historical data are collected from different sources and cleaned. 2nd build 3D Model to produce more realistic Environment for heritage building and insert 3D model to GIS. 3rd the abstraction of spatial relations is done by using GIS components (map objects components). 4th the data is transformed into appropriate form for ANN (normalized). 5th Matlab is used for building a prediction model using ANN (training-testing-validating). This step is done by linking the Matlab with desktop application. 6th after finishing the model is used by inserting a dataset of current data and get predicted values as an outputs.7th the output values are passed to GIS components and represented visually as 3D modeling technique. The output will be a predicted remaining time of heritage building in the near future depending on the historical and current data and status.

\section{CONCLUSION}

Architectural heritage is affected by natural effects. Also, it is threatened by recovery and reconstruction works.As a result, restoration works may be required. Measured drawings which show the original state of the structure are used for restoration works for many years.

The developed framework will contain the strength of GIS, 3D Photogrammetric technique and ANN. So, it will be useful in assessment of decision maker in complex spatial problems. This integration will lead to extend GIS to develop modern GIS (traditional GIS with AI capabilities) and therefore can be used as a Spatial Decision Support System (SDSS).by the application of Geographical Information Systems (GIS) that can describe and analyze the decision and Artificial Neural Networks (ANN) context to synthesize these data to assist decision makers in their choices.3D model to produce more realistic and detailed environment for preservation of heritage building. This model presents a unique combination of those important tools. It is also a decision model defining the various features of the main actors in the process. In a few words, the conceived structure is a data base which tells the story of Heritage buildings history by means of different kinds of documents (texts, pictures, drawings, 3D model); which preserves the buildings' identity, its origin and changes through the memory of the past and the knowledge of present. Finally, it is a way to hand down to future generations the history of the architecture building and its changes.

\section{REFERENCES}

[1] Zaide DURAN, Caner GÜNEY, Assoc. Prof. Dursun Z. SEKER andProf. Gonul TOZ, Turkey.2002: Using GIS Technology for the Documentation of Historical Monuments, FIG XXII International Congress Washington, D.C. USA.

[2] Hasan YILDIZ, M. Umit GUMUSAY.2011:3D Modeling Of The Çukursaray (The Hollow Palace), Istanbul - Turkey And Its Application For Campus Information System, International CIPA Symposium, September 12-16

[3] http://www.giscenter.gov.eg/sca-archaeological-sites/egyptmap/ad-daqahliyyah/islamic/muhammad-bik-ash-shinnawipalace? func $=$ slideshow

[4] Franca RESTUCCIA1, Mariateresa GALIZIA1, Cettina SANTAGATI1.2011: A GIS For Knowing, Managing, Preserving Catania's Historical Architectural Heritage,The International Committee for Documentation of Cultural Heritage (CIPA), December.

[5] Ahmed LoaiAli, Osman Hegazy , MohammedNourEldien .2010:A Framework for integration between Artificial Neural Network \& Geographical Information System, Slum prediction as the case study, International Journal of Electrical \& Computer Sciences IJECS-IJENS Vol: 10 No: 01, February.

[6] Maria Daniela Tantillo.2007: GIS Application in Archaeological Site Of Solunto, XXI International CIPA Symposium, 01-06 October, Athens, Greece.

[7] Jeff Thurston.2002: GIS\& Artificial Neural Networks: Does Your GIS Think?, GISCafe.com, January.

[8] F. Karsli a, *, E. Ayhan a, E. Tunc a2005: Building 3d Photo-Texture Model Integrated With GIS For 
Architectural Heritage Conservation, The International Committee for Documentation of Cultural Heritage (CIPA), September.

[9] S.Günay a.2007: Spatial Information System For Conservation Of Historic Buildings Case Study: Do_Anlar Church_Zm_R, Volume XXXVI-5/C53, 2007 Proceedings of the 21st CIPA symposium AntiCIPAting the future of the cultural past, October 1-6.

[10] Tunc E., Karsli F., Ayhan E.2004:3d City Reconstruction By Different Technologies To Manage And Reorganize The Current Situation,XXth ISPRS Congress Technical Commission IV, Turkey, July 12-23.

[11] Abdul GhaniSarip.2005: Integrating Artificial Neural Networks And GIS For Single Property Valuation, PRRES Conference, January.
[12] ChanguiPeng1 and Xuezhi Wen2.1999: Recent Applications of Artificial Neural Networks in Forest ResourceManagement: An Overview,In: U. Corté and M.Sànche-Marrè (Eds.).Environmental Decision Support Systems and Artificial Intelligence. pp. 15-22, AAAI Technical Reports WS-99-07, AAAI Press, Menlo Park, CA.

[13] FatimaZohraYounsi*,DjamilaHamdadou*, KarimBouamrane*.2008: A Decision-Making Model For Territory Planning: Integration Of GIS And Artificial Neural Networks.

[14] Z. Durana, A. GaragonDogrub, G. Toz a.2005 :Cultural Heritage Preservation Using Internet-Enabled GIS ,The International Committee for Documentation of Cultural Heritage(CIPA),September 